\title{
ПСИХОИСТОРИЯ НА ПОСТСОВЕТСКОМ ПРОСТРАНСТВЕ: ИСТОРИОГРАФИЧЕСКИЙ ОБЗОР
}

В статье представлен обзор развития психоистории на постсоветском пространстве. Автор излагает выводы проведенного исследования, касающиеся методологических проблем психоистории, её соотношения с исторической психологией, социологией, другими гуманитарными дисциплинами. Отмечается также недостаточность философского осмысления психоистории, хотя ёё антропоцентричность является безусловной.

Ключевые слова: психоистория, историография, антропоцентризм.

Гуманистический подход в оценке исторического процесса на современном этапе приобрёл активный характер. В данном контексте историческая психология давно утвердила свои позиции, тесно связав себя с культурологией. Достаточно вспомнить такие яркие фундаментальные работы, как, например, Й.Хёйзинга «Осень Средневековья» ${ }^{2}$, где автор изначально поставил перед собою цель исследования форм жизненного уклада и форм мышления в XIV-XV во Франции и Нидерландах, что непосредственно показывает нам психологию различных социальных групп и соответствующие сценарии поведения.

М.Вебер, говоря, о генезисе духа капитализма, тесно связывает его с идеологией протестантизма, с теми преодолёнными социальными установками и стереотипами, которые в своё время породил католицизм ${ }^{3}$. Этот перечень можно было бы продолжать долго, если бы не одна проблема: методологический кризис всегда маячит перед исследователем. Каковы же дальнейшие перспективы в исследовании феномена психического в историческом процессе, в методах исторического познания?

Концепция Ллойда Демоза, получившая название психоистории ${ }^{4}$, дала новый метод, который в западной науке создал мощную платформу слияния исторического исследования, социальной психологии, психоанализа и других современных социально-гуманитарных наук.

Целью данной работы является исследование современного состояния психоистории в историографическом контексте, специфики развития психоистории на постсоветском пространстве, в Украине в частности.

В создании идейно-политической базы психоистории лидирующую роль сыграл

\footnotetext{
${ }^{1}$ Dr Anna Czeczelnickaja Vladimirovna, docent Katedry Nauk Humanistycznych Państwowej Akademii Finansowej w Dniepropietrowsku, Ukraina.

${ }^{2}$ М. Вебер, Протестантская этика и дух капитализма. - М.: ИНИОН, 1991.

${ }^{3}$ Й. Хёйзинга, Осень Средневековья. - Москва: «Изд-во Наука», 1988.

${ }^{4}$ Демоз Л., Психоистория. - Ростов-на-Дону, 2000.
} 
фрейдизм: ещё Зигмунд Фрейд в соавторстве с У.Буллитом выпустил книгу «Вудро Вильсон. Двадцать восьмой президент США. Психологический портрет». В 1922 году в американском научном журнале «Психиатрический обзор» вышла работа Р.В.Херроу «Психологические исследования Сэмуэла Адамза». Российский исследователь М.В. Кирчанов, историографический анализ которого для нас является базовым ${ }^{5}$, полагает, что именно с этой работы следует начинать психоисторическое исследование революций. Исследование же истории детства начинают О.Крисман, С.Левин.

В 1930-тые годы единого центра психоисторических исследований не существовало, и они велись в разных странах. Первое место в них занимает Германия. Англоязычные работы увидели свет в США.

Российский учёный делает принципиальное замечание о том, что ещё в 1930-тые г.г. формируется психоисторический подход к проблеме соотношения культуры и развития личности; человека и его места в обществе; ребёнка и государства; история воспитания детей и семья в Великобритании. А в 1940-ые г.г. ситуация кардинально меняется: исследовательским центром становятся США.

Психоистория в современном виде формируется в 1950-ые г.г., когда психоисторические методы привлекаются в исследовании истории религии. Именно тогда, по Кирчанову, происходит становление методологических основ психоистории, когда появляется работа У.Ленгера, которая имела название «Ближайшие цели». В ней было обозначено необходимость для историков владеть методикой психоанализа.

В 1960-ые г.г. позицию исследователя-лидера занимает Эрик Эриксон. Б.Мезлиш делает попытку обосновать необходимость применения психоистории для изучения групповой психологии и социальных проблем современной истории. Значительная часть исследователей, отмечает автор историографического обзора, главной темой выбирают теоретические проблемы революции как таковой.

На наш взгляд, важной и современной по духу является монография Ф.Вейнстейна и Г.Плетта, которая посвячена стремлению личности к свободе «The Wish to be free" (L.A., 1960). По мнению исследователя, расцвет психоистории выпадает на 1970-ые: в 1976 году в Нью-Йорке под редакцией Г.Крена та Л.Рапопорта выходит колективное теоретическое исследование «Разнообразие психоистории». Появляются специализированные журналы. Трудно не согласится с исследователем, что наиболее авторитетным является «Журнал психоистории», который редактировался Л.Демозом, ставшим главным лидером и теоретиком психоистории. Темы, которые наиболее часто рассматриваются в журнале: история детства, истоки войны и насилия, проблемы американской истории, наказания детей и их связь с политическими отношениями, холокост и история детства в Германии. Помимо периодических зданий возникают психоисторические научные организации, например, МПА - Международная психоисторическая ассоциация.

В 1970-ые г.г. наблюдается процесс накопления психоисторических знаний, а также формирования методологии данной дисциплины. П.Монако рассматривал

${ }^{5}$ М.В. Кирчанов, Психоистория// Ресурс доступа:http://www.bim-

bad.ru/biblioteka/article_full.php?aid=1523\&binn_rubrik_pl_articles=112 
соотношение психоистории с другими областями научного знания, ставя главный вопрос является психоистория независимой наукой. Ф.Мануэл говорит о том, можно ли использовать методы психологии в исторических исследованиях и корда это может кметь негативне последствия. К нему присоединились Р.Шёнвалд, Р.Бинтон, П.Лёвенберг. Б.Мезлиш попытался найти наиболее благоприятную дифиницию для определения психоистории как науки, делая попытку связать её с современным ему состоянием науки. В этоже время Ф.Вейнстейн прогнозирует методологический кризи психоистории, устанавливая соотношение социологии и психологии.

На современном этапе наибольших успехов психоистория достигла в США, где действует Институт психоистории и издаются специализированные журналы. Трагические события «11 сентября» простимулировали Ллойда Демоза дать психоисторическую оценку такой глобальной современной проблеме как тероризм, что свидетельствует о реализованной социальной функции психоистории.

После падения Советского Союза и формирования баз национальных наук в новосозданных государствах постсоветского пространства, которые столкнулись с методологическим кризисом в следствие отказа от марксистко-ленинской методологии как доминирующей, психоистория становится объектом нового осмысления.

Наиболее широкий историографический обзор делает уже упомянутый выше российский исследователь М.В.Кирчанов. В 1997 году в Минске выходит монография О.М. Шутовой "Психоистория: школа и методы", оценку которой даёт московский учёный Д.М.Володихин: «О.М. Шутова дает краткую историю институализации психоистории как самостоятельной дисциплины (с перечислением наиболее значительных исследовательских учреждений) и предлагает ее дефиницию, принадлежащую американскому исследователю В.М. Раньяну. Это определение основано на выявлении концептуальных различий истории и психологии: "психоистория направлена на использование психологических теорий в исторических интерпретациях; историческая психология - на изучение трансисторических общностей или специфических психологических структур, их элементов и взаимоотношений в истории; история с психологическим содержанием - на выяснение степени влияния психологических феноменов (человеческих мотиваций, верований, эмоций и действий) на историческое развитие" ${ }^{6}$. На наш взгляд, очень важной является попытка философского осмысления психоистории автором монографии и её рецензентом, а также определение разницы между психоисторией и исторической психологией.

В последние годы наблюдается процесс использования психоистории как метода в диссертационных исследованиях учёных Российской Федерации для изучения исторических личностей. Например, диссертационное исследование на соискание степени кандидата исторических наук В.В. Ахтямова «Психоисторические аспекты

\footnotetext{
6 Д.М. Володихин, Здравствуйте, госпожа психоистория!// Ресурс доступа: www.ab.ru/ kleio/aik/bullet/22/38.shtml.
} 
жизни С.Ю.Витте и П.А.Столыпина» ${ }^{7}$. Определяя изучение исторической личности как одну из главных проблем исторической науки, исследователь делает замечание о том, что, не сомневаясь в объективности общественно-политических и социальноэкономических процессов, обусловивших проведение в Российской империи важнейших реформ, учёные, однако, не могут не признать, что способы, а главное характер и масштаб преобразований были в определенной степени обусловлены личностной позицией С. Ю. Витте и П. А. Столыпина. Используя дефиницию и методы психоистории, таким образом, В.В. Ахтямов делает такие основные выводы:

- Психоистория как наука характеризуется для нас не материалом, которым она занимается, а техникой, при помощи которой она работает. И, скорее всего, именно переломные исторические эпохи, когда сужается привычный горизонт бытия, и господствуют настроения разочарования, страха, подавленности и неуверенности социума (Э. Эриксон называет их периодами вакуума идентичности) должны вызвать особенный интерес у психоисториков. (Понятие «вакуума идентичности», полагаем, является ключевым для украинской народности, нации, развитие которой проистекало основную часть истории в рамках иных государств). В частности, это относится к психобиографам, задача которых состоит в том, чтобы соотнести психосоциальные потребности личности с нуждами ее исторического времени. В конечном счете, написание психоисторического портрета выдающейся личности состоит в раскрытии социально-психологических потребностей эпохи, которые, впоследствии, консолидируются в новую идеологическую парадигму. И наша задача, отмечает учёный, - через психоисторический портрет творческой личности проанализировать смутные умонастроения переходных исторических эпох. На наш взгляд, использование именно таких определений как «смутные умонастроения», «социально-психологические потребности эпохи» и т.д. формируют живое, не схематичное ощущение истории, без которого невозможно качественное погружение в историческую реальность.

- Важным методологическим пояснением является то, что психоистория изначально ставила перед собой задачу не столько описывать, сколько объяснять произошедшие события. Метод психоистории предполагает свою методологию открытия, которая пытается решить проблемы исторической мотивации при помощи сочетания исторических документов, психоанализа и собственного эмоционального опыта исследователя. Но в отличие от методов психоанализа, психоистория ориентирована на исторические источники и понимание изменчивости культурно-исторических форм.

- Рубеж XIX - XX веков является периодом, когда на политическую авансцену выходят люди нового типа мышления. Предпосылкой формирования этого нового типа стал прогресс в воспитании детей, начавшийся в середине XIX века. Психоисторик Ллойд Демоз назвал данный этап эволюции детскородительских отношений «социализирующий стиль». Масштабные изменения в стиле воспитания дают толчок историческому движению. Изменения в устройстве

${ }^{7}$ В.В. Ахтямов, Психоисторические аспекты жизни С.Ю.Витте и П.А.Стольпина//Автореферат на соис.науч.ст.канд.ист.наук//www.dslib.net/istoria-otechestva/ahtjamov2.html/ 
общества, в политике, в экономике, в технологии происходят не сами по себе, а являются следствием появления на исторической арене нового типа личности. Сергей Юльевич Витте и Петр Аркадьевич Столыпин были теми государственными деятелями, которые представляют характерный пример людей нового типа в истории.

- $\quad$ Верхушка столичной бюрократии была не в состоянии справиться с новыми тенденциями в развитии России, понадобились реформаторы нового типа. Яркой особенностью С. Ю. Витте и П. А. Столыпина был их провинцианализм, лишенный высокомерности столичного общества. Знание жизни изнутри, из практической деятельности, а не из докладов служащих и литературы - вот главное достоинство чиновников нового типа. Оба начали службу в провинции, каждый в своей области прошел все ступени служебной карьеры. Высшее образование С. Ю. Витте и П. А. Столыпин получили в университетах, специализируясь на естественных науках (физико-математический факультет). У обоих были старшие братья, рано ушедшие из жизни. На формирование мировоззрения, идеалов и жизненных принципов сильнейшим образом повлияли родные дяди. В семейной жизни у обоих реформаторов также обнаруживается много общего. Многочисленные письма к женам, проникнутые сентиментальным настроением и заботой о детях, раскрывают схожий душевный мир С. Ю. Витте и П. А. Столыпина.

- $\quad$ Главной составляющей деятельности С. Ю. Витте и П. А. Столыпина на разных должностях была ответственность за порученную работу, а также проницательная интуиция, которая позволяла им выделять из массы людей представителей своего типа. Они, искренние монархисты и патриоты, были, также, последовательные противники военных конфликтов - антимилитаристы. Как государственные деятели С. Ю. Витте и П. А. Столыпин настолько превосходили всех своих современников, что, в конечном счете, стали раздражать Николая II, и как только представлялся случай, император старался избавиться от своих министров. Хотя заслуги обоих реформаторов перед страной признавали различные политические и общественные круги, тем не менее, врагов у министров при жизни и после смерти всегда было предостаточно.

- $\quad$ При стольких схожих моментах существенное различие этих двух деятелей не вызывает сомнения. Споры государственного и личного характера С.Ю.Витте и П. А. Столыпина демонстрируют как историческую, так и психологическую противоположность. П. А. Столыпин являлся классическим примером интровертного типа личности. Его сильный, оригинальный и проницательный интеллект сопровождался очевидной в личном общении чувственностью. Процесс психологического развития привел его к жертве, которая, при всей абсурдности такого эпилога, является логическим концом жизненного пути данного индивида. Наоборот, яркий, подвижный, конъюнктурный экстравертный тип, представителем которого был С. Ю. Витте, не смог удержаться во власти и медленно догорел в бесплодных попытках вернуться. Отличие черт характера С. Ю. Витте и П. А. Столыпина, выявленное на основе теории Э.Кречмера, позволяет глубже исследовать личности социализирующего стиля. Различные подходы к реформированию империи имеют своей основой внутреннюю несовместимость двух государственных деятелей. Спонтанная, лишенная какой-либо программы работа П. А. Столыпина явилась, в конечном итоге, накоплением многочисленного 
материала при незначительных результатах. Напротив, эмоциональный выплеск С. Ю. Витте направлен на конкретные задачи и, как следствие, проведенные мероприятия складываются более удачно.

- $\quad$ Отсутствие страха за свою деятельность, у Столыпина даже за свою жизнь, вызвано пониманием, что власть, которую они оба любят и стремятся к ней, не сможет обойтись без них, а результатом этого становится заметное проявление авторитарных наклонностей. Поэтому постоянный рост числа недоброжелателей при таком развитии личности, думается, закономерен.

- $\quad$ Отставка 1903 года С. Ю. Витте существенно повлияла на его отношение к обществу в целом. Он оказался неоценен, не понят и, следовательно, у опального сановника крепнет ярко выраженное стремление к реабилитации себя в глазах того самого общества, которое от него отвернулось. Портсмутский мирный договор 1905 года вернул С. Ю. Витте во власть, а также способствовал росту его международной популярности. Но это привело к новому всплеску недовольства со стороны самых разных политических и государственных кругов. Последующая деятельность С. Ю. Витте на посту председателя Совета министров окончательно подорвала как его здоровье, так и положение в обществе. Устранение «Великого визиря» от государственной деятельности в 1906 году явилось полным крахом всех надежд на преобразование Российской империи в соответствии с его идеалами. Оставаясь членом Государственного совета, С. Ю. Витте именно здесь впервые столкнулся с П. А. Столыпиным, тоже новым типом государственного деятеля. Отсюда, свойственная С. Ю. Витте истеричность, выплеснулась на все начинания П. А. Столыпина. Бывший премьер-министр, таким образом, оказался на месте своих бывших завистников и даже в одном с ними лагере. Глубокая неприязнь С. Ю. Витте к П. А. Столыпину и холодная отчужденность последнего четко проявлялась в их переписке и личных контактах. Перед нами психологические различия двух типов личности, которые вскрывают самые глубинные мотивы конфликта этих государственных деятелей.

- Историческая эпоха обусловливается психосоциальным соотношением личности и социума, их существенным взаимовлиянием. В переломные исторические эпохи, выдающиеся личности выступают глашатаями выдвинутых историческим временем идей, которые они оформляют в новую идеологическую парадигму. Таким образом, творческая личность оказывается связанной со своей эпохой не только на уровне сознания, но и через иррациональные структуры духовной жизни общества, а ее социальное новаторство, питаясь интеллектуальной традицией, является в то же время оформлением умонастроений эпохи.

Выводы, сделанные В.В. Ахтямовым, являют собой яркую иллюстрацию того, как психоистория раскрывает глубинные срезы характеристик явлений. Использование таких, казалось бы, лишённых плотной телесности категорий, как «раздражение Николая II на П.А.Столыпина», «стремление идти наперекор большинству», «психологическая противоположность - интровертивность Столыпина и экстравертивность Витте» показывают нам современное измерение такого явления как роль личности в истории. Методологическое углубление этой проблемы делается в следующее диссертационном исследовании: «Социальнопсихологический аспект изучения истории в российской историографии последней трети XIX - первой половины XX вв.» В.В. Шувалова на соискание научной 
степени доктора исторических наук ${ }^{8}$.

Таким образом, мы подходим к актуализации использования психоистории в политической практике и в политологической теории. Своё слово в данном контексте сказала Украина, создав в Киеве Школу политической психологии. Её основателем и популяризатором является Г.Балашов, сделавший на основании методов психоистории психологические портреты наиболее известных украинских политиков.

Психоистория имеет физическую и астрофизическую основу. По мнению донецкого исследователя В.А.Моргуна ${ }^{9}$, вся психоистория человечества - это череда пульсаций в ритмах Космоса, подъём и угасание сенсорно-колективистского «Света» в рационально-индивидуалистической «Тьме», возрождение и расцвет цивилизаций в «тихие времена» и умирание в условиях «квантовой нестабильности». Исследователь усматривает закономерный характер данных пульсаций и объединяет их в единую периодическую систему циклов Космоса, природы, общества, человека. Завершение макроциклов, связанных с парамагнитными резонансами различной степени разрушения, сопровождается стихийными бедствиями и социальными кризисами.

Отрадно также констатировать тот факт, что психоистория стала учебной дисциплиной в ВУЗах. Примером может служить программа спецкурса «Психоистория» Уральского университета Российской Федерации, а так же изучение психоистории как отдельной темы в рамках предмета «Методология истории» Гродненского государственного университета имени Янки Купалы ${ }^{10}$.

Итак, говоря о состоянии психоистории как научной дисциплины и метода исторического исследования, мы можем сделать такие выводы:

1. С развитием национальных наук на территории постсоветского пространства прослеживается постоянный интерес к психоистории.

2. Основные методологические вопросы, связанные с психоисторией: её соотношение с исторической психологией, психологией, социологией, другими социальными дисциплинами, особенно в контексте выяснения методологических возможностей и границ психоистории.

3. Идёт активизация использования психоистории как метода в исследовании биографий исторических деятелей.

4. Психоистория имеет дальнейшие перспективы для развития в слиянии с другими науками, например, с физикой и астрофизикой для выяснения взаимосвязи исторических событий с космическими циклами и фазами пассионарности; с политологией.

5. Используя психогенную теорию развития общества, предложенную Л.Демозом, возможно создание психоисторических концепций национальных

${ }^{8}$ В.В. Шувалов, Социально-психологический аспект изучения истории в российской историографии последней трети ХIX - первой половины XX вв. // Автореферат на соис.науч.ст.док.ист.наук//www.dslib.net.

9 В.А Моргун, Квантовая психоистория о связи макрофракталов «волн пространства-времени» с глобальными катаклизмами.І Ресурс доступ: postmaster@morgun.donbass.com

${ }^{10}$ Pecypc доступа: psy.usu.ru/disc/Программа Психоистория; Ресурс доступа:

fh.grsu.by/Kafedry/03/academic_process/013/Uch_prog. 
историй, в частности украинской, в чём мы определяем для себя дальнейшую цель.

6. Прослеживается недостаток философского осмысления психоистории, хотя безусловной является ёё антропоцентричность и способность внести новые параметры в оценке роли личности в истории, а также в проблеме соотношения свободы и личности, - и это только приблизительный круг вопросов. Восполнение данной ниши позволяет продуцировать новые цели исследований.

7. Данная дисциплина вошла в учебное пространство как для студентовисториков, так и для студентов-психологов.

\section{ЛИТЕРАТУРА}

[1] Ахтямов В.В., Психоисторические аспекты жизни C.Ю.Bитте $u$ П.А.Столыпина//Автореферат на соис.науч.ст.канд.ист.наук//www.dslib.net/istoriaotechestva/ahtjamov2.html/.

[2] Вебер М., Протестантская этика и дух капитализма. - М.: ИНИОН, 1991.

[3] Володихин Д.М., Здравствуйте, госпожа психоистория!// Ресурс доступа: www.ab.ru/ kleio/aik/bullet/22/38.shtml.

[4] Демоз Л., Психоистория. - Ростов-на-Дону, 2000.

[5] Кирчанов М.В., Психоистория// Ресурс доступа:http://www.bimbad.ru/biblioteka/article_full.php?aid=1523\&binn_rubrik_pl_articles=112

[6] Моргун В.А., Квантовая психоистория о связи макрофракталов «волн пространства-времени» $c$ глобальными катаклизмами.॥ Ресурс доступ: postmaster@morgun.donbass.com

[7] Ресурс доступа: psy.usu.ru/disc/Программа Психоистории.

[8] Ресурс доступа: fh.grsu.by/Kafedry/03/academic_process/013/Uch_prog.

[9] Хёйзинга Й., Осень Средневековья. - Москва: «Изд-во Наука», 1988.

[10] Шувалов В.В., Сочиально-психологический аспект изучения истории в российской историографии последней трети XIX - первой половины XX вв. // Автореферат на соис.науч.ст.док.ист.наук//www.dslib.net.

\section{PSYCHOHISTORIA NA PRZESTRZENI PORADZIECKIEJ: PRZEGLĄD HISTORIOGRAFICZNY}

W pracy przedstawiono przegląd rozwoju psychohistorii na przestrzeni poradzieckiej. Autorka formułuje wnioski $\mathrm{z}$ własnego badania, dotyczącego problemów metodologicznychtej nauki, jej relacji z psychologią historyczna, socjologia, innymi dyscyplinami humanistycznymi. Ponadto w artykule zaznacza się, że ujęcie filozoficzne psychohistorii jest nie wystarczające mimo niepodważalności jej antropocentryzmu.

Kluczowe slowa: historia, psychohistoria, antropocentryzm.

\section{PSYCHOHISTORY IN THE FORMER SOVIET UNION: HISTORIOGRAPHICAL REVIEW}

The article reveals the historiography of psychohistory in the FSU. The main conclusions of the study are: the main issues related to psychohistory - methodological: its relationship to historical psychology, psychology, sociology and other social subjects can be traced the lack of philosophical understanding of psychohistory, although it is unconditional anthropocentricity.

Keywords: the historiography, the psychohistory, anthropocentricity.

DOI:10.7862/rz.2012.einh.8 